\title{
A net based solution for lifecycle engineering
}

\section{Concepts and requirements}

\author{
A. Bechina, U. Brinkshulte, K.Synnes*, O:E: Artzen** \\ $I P R$, Institute for Process Control and Robotics, Universiy of Karlsruhe, Germany, \\ *Centre for Distance-spanning Technology, Luleå University of Technology, Sweden, \\ ** Teknometri, consulting company, Oslo, Norway
}

\begin{abstract}
A product life-cycle requires product engineering effort starting right from the product idea and ending for i.e. with support for product recycling. In the framework of the European project mediasite [10], our study focuses on the combination of product engineering and Web technologies in order to decrease the cost. Therefore we defined the term of Integrated Product Engineering (IPE) as the concept integrating people, technology and information into a net based solution for life cycle engineering. This e-engineering collaborative platform lead to the concept definition of an extended enterprise. This paper presents the concepts and requirements for developing a net based solution. The functionality of a such platform is outlined.
\end{abstract}

Key words: Integrated Product Engineering, collaborative platform, extended enterprise

\section{OVERVIEW}

Today the characterisation of global competition relies on the needs to decrease the cost, improve the customer satisfaction, time-to market, etc. Competitive companies today focus on the combination of an Integrated Product Engineering (IPE) effort and World Wide Web use. We define Net based IPE as a management strategy that uses customer requirements, crossfunctional teaming, information process and technology integration to improve the performance of Product Engineering lifecycles. IPE should provide universal methodologies that answer the fundamental questions briefly described here:

- "What to do" means what activities and results are to be achieved in the course of an engineering process.

The original version of this chapter was revised: The copyright line was incorrect. This has been corrected. The Erratum to this chapter is available at DOI: 10.1007/978-0-387-35492-7_50 
- "How to do it" means how the engineering processes realise the activities and results. This level involves the determination of the appropriated methods in order to perform the activities and results.

- "With what" means what technologies and methods have to be used or designed in order to achieve the engineering processes.

This questions reflect the different perspectives that should be taken in account in an IPE effort such as functional, behavioural, informational, organisational and operational aspects [1].

The first stage of the project focused on defining a methodological framework on how organisations/enterprises could move toward a totally electronic representation of the product and its processes. The elaborated methods rely on the principle of allowing early data sharing and greater concurrency in the Product Engineering lifecycle. The need to provide a practical approach to share data and support strong structured processes have led to the specification of a technological infrastructure defined as an eengineering collaborative platform [10].

The goal of this platform is to provide an adequate infrastructure that enables people to collaborate in developing and maintaining product over geographical distances, directly modifying data at the customer's site or at the development centre. Collaboration is a critical issue. Internet and intranets make this function cost-effective and provide the means to support a highly interactive, collaborative workforce.

The challenge in the solution platform definition focuses on :

- the requirements specification of IPE in order to realise collaborative strategies,

- the specification of collaborative functions and their Mapping within the product engineering process in order to be fast and cheap at each stage of the IPE effort,

- the specification of a new extended enterprise model seen here as network of manufacturers, partners, customers involved in the IPE Processes,

- analysis of the integration between people, technology and information

The next part of our paper introduces the definitions of an Integrated Product Engineering (IPE) and the basic principle of the methodologies for lifecycle IPE.

The third part proposes an extended enterprise model and focus on the integration process requirement.

The fourth part introduces the e-engineering platform and its main functionality.

The last part outlines some conclusions. 


\section{INTEGRATED PRODUCT ENGINEERING PROCESS DEFINITION}

The IPE process covers the process from the idea of a product to its market entry. It is defined as set of activities, concurrent processes which are required to generate the necessary information about the product, its production, logistics, marketing efforts etc.

The basic foundations of the methodology lead on definition of a generic activity model and generic process model which cover all the phases/lifecycle of IPE [2].

\subsection{Definition of a generic activity model}

A generic activity model can be described by a piece of work that forms one logical step within a process [4],[5]. An activity may be

a) a manual activity, within an engineering process which is not capable of automation. Such activities may be included within a process definition, for example to support modelling of the process, but do not form part of a resulting workflow.

b) a workflow (automated) activity, which is capable of computer automation using a workflow management system to manage the activity during execution of the engineering process of which it forms a part.

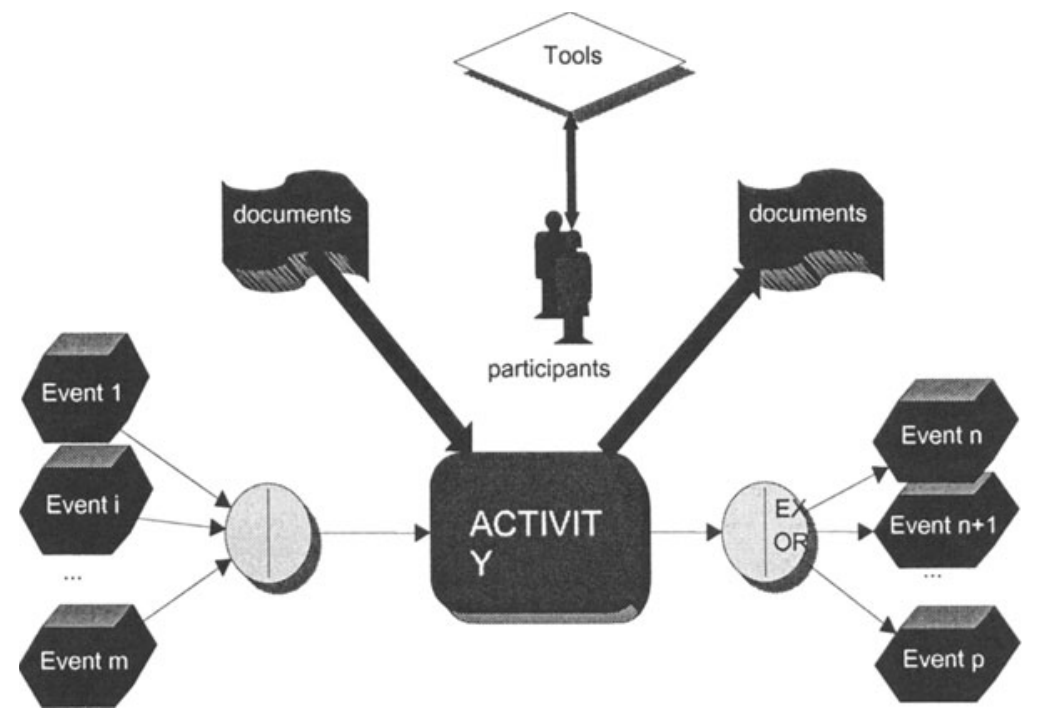

Figure 1. Inputs and outputs of an activity

A workflow requires human and/or machine resource(s) to support process execution. An activity is allocated to workflow participant, where 
human resource is required. A more detailed and complete definition can be found in [2]

- Each activity has a start date (min, max) and an end date (min, max).

- Each activity has an intermediate result which defines the goals of the tasks.

- For each activity a person or a team is affected

- Document or in wider sense, resources have to be defined in case of use, modification, and producing.

\subsection{Definition of Generic Process models}

An Integrated Product Engineering process is defined as set of Activities which are required to generate the necessary information about the product and its development [2].

The generic processes applied to a typical Integrated Product Engineering is decomposed into several sub-process called Workpackages and are described as following:

- Analysis/specification defines the product requirements in a product concept. This phase is primarily interested in capturing the customers requirements and specifying the technical properties of the product.

- Product design phase

- Quality Function deployment including the test and simulation. It describes as well a product on the basis of testing procedures and inspection plans that are necessary to ensure quality-related properties.

- Product development of manufacturing processes and supporting information and prototyping the product.

For products which are assembled from parts and subassemblies, these functions must be performed for all complex components as well as the final product.

Workpackages allow to structure the whole project and form a hierarchy.

The generic process and activity models allow to plan and create long term or ad hoc extended enterprises that gather all the actors (customers, manufacturers, partners, ..) involved in a common IPE process. The sequential or concurrent processes engineering are distributed among the industrial actors and thus lead to definition of an extended enterprise model. 


\subsection{Process Integration $\rightarrow$ Extended enterprise model definition}

A true net based solution for IPE requires the integration of people, business processes and information technology across the life cycle engineering. The technology must support the business/engineering process by enabling the users to get their tasks done and link them to others in the process. This means interfacing application and sharing data across organisational functions as well as with suppliers and customers.

Important issues have been identified such enterprise applications interoperability, security aspects, electronic procurement, distributed engineering/business process management, technologies and standards, etc.

In this paper we focus briefly and mainly on :

- identification and specification of the integration level (information, people, application, ..),

- identification and specification of collaborative functions

The Product Engineering cycle for complex products, four dimensions of integration that must be supported by the technology in an enterprise level IPE system could be considered:

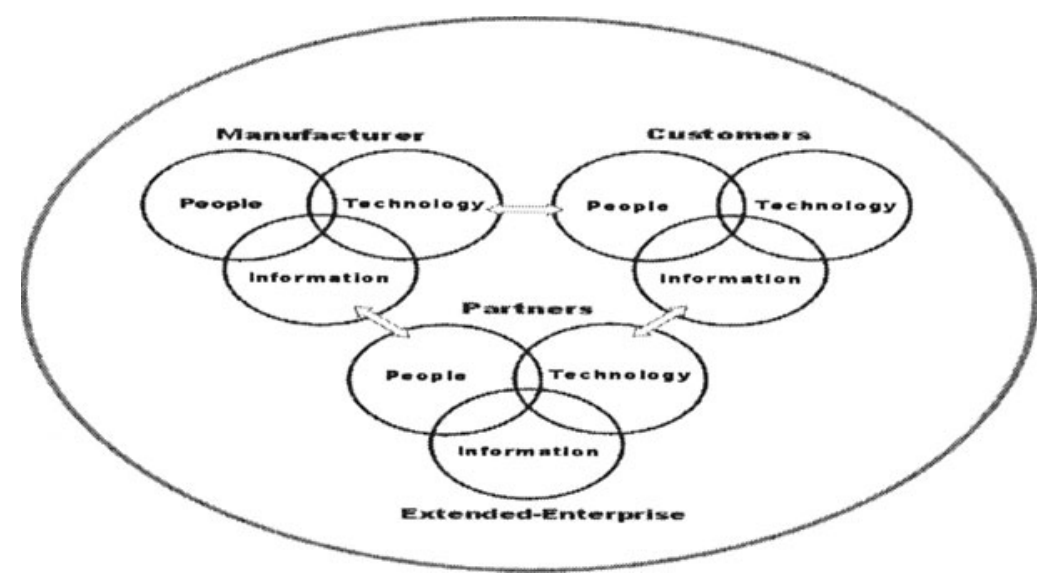

Figure2: Extended enterprise model

1. the integration of the business process (concept to design to manufacturing) for a particular project dealing with a component or subassembly,

2. the integration of the workflow and applications that support the tasks in the project,

3. the multiple projects must be co-ordinated by program or person that deals with the entire assembled product, 
4. and finally, the organisations that participate in the implementation of the IPE platform, including suppliers, vendors and the manufacturer should be integrated.

The four dimensions of an IPE require integration of information technology in three traditional IT domains:

1. Technical applications also referred as CAx (computer-aided-everything: CAD, CAE, CASE, ..), tend to be specialised and are used "vertically" within one discipline or function (i.e. design, analysis, testing, process planning, part programming, etc.) within the product engineering cycle. Technical applications may be interfaced horizontally across disciplines, but this is still complicated by the fact that different views of the data occur in different disciplines. Though today some emerging standards such as, EDI , XML, etc. allow to exchange or share the same data.

2. Management applications are used to enable structured business processes through cross-functional workflow, budgeting, scheduling and data/document management.(workflow, project management, product data and document management, ...)

3. Personal productivity tools promote unstructured or ad hoc linkages along the product engineering lifecycle (word processors, document management, calendar, voice mail, etc. They play an important role in the definition of the collaborative functions.

The integration of applications is complicated by functionality overlap between various categories of applications. And the validity of an extended enterprise model rely on the development of a support integrating people, technology and information.

The first step dealing with integration issues has helped to the definition of the functionality requirement of the technological infrastructure. A netbased IPE platform should offer a wide range of functions, including engineering information management, engineering change management, product structure management, etc. However in this paper we introduce only the fundamental aspects concerning mainly the development of collaboration/communication means and the data sharing functions.

The next section introduces the collaborative platform and its needed functionality. 


\section{AN E-ENGINEERING COLLABORATIVE PLATFORM}

\subsection{Reference model}

Every organisation has different priorities, different implementations strategies, and will, as result require different levels of IPE capabilities. However some common function are outlined in this section.

The extended enterprise model rely on a strong need to build new and better relationships with all the economic actors involved [6],[7],[8]. Those requirements could be achieved by connecting all the players in the processes into a common collaborative platform that should encompass the following functions: discussion forum, news, document management, chat, e-meeting, authoring, engineering, training, etc.

In the framework of our work, a reference model of this platform has been outlined and comprise the following components:

- User

- Product Engineering services

- Operating system services Each of the services also relies on the standard operating system basic services. These services include: communication (mainly TCP/IP), disk storage, system administration, backup/restore, logging, monitoring

- Certificate Authority (CA): plays an important role in a Public Key Infrastructure (PKI). The Certification Authority (CA) is a trusted thirdparty entity, with well-known and advertised service access points for use by clients. The CA is the authority providing services for creating, administrating, publishing and revoking (cancel) digital certificates.

- Core services described in the next section

- Interfaces

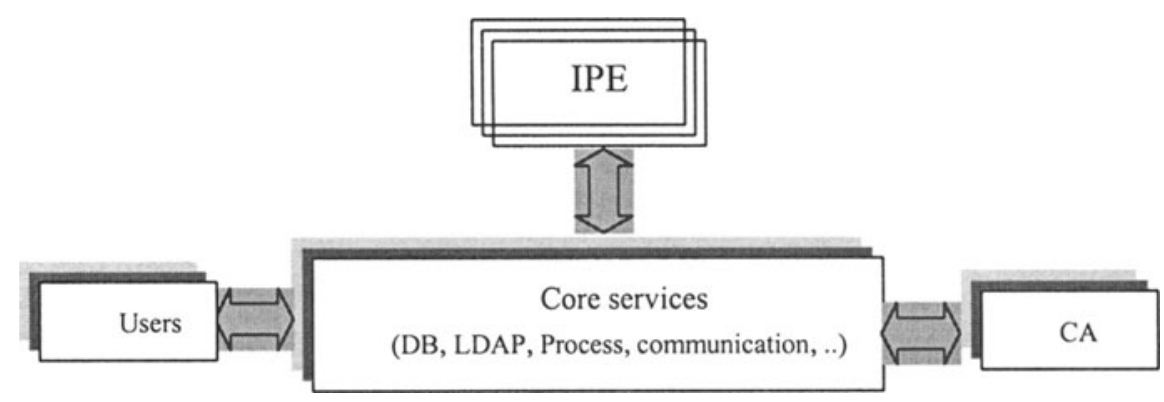

Figure 3: reference model 
The next section describes the core services of the collaborative platform.

\subsection{Services provided by e-engineering platform}

\begin{tabular}{|c|c|c|}
\hline \multicolumn{2}{|c|}{ Service } & \multirow{2}{*}{$\begin{array}{l}\text { Functions } \\
\text { Provide the correct user rights }\end{array}$} \\
\hline & User management & \\
\hline & PostMaster & $\begin{array}{l}\text { Can receive different forms of input } \\
\text { such as paper documents, email, fax, } \\
\text { EDI. }\end{array}$ \\
\hline & News & $\begin{array}{l}\text { Provides support for individual news } \\
\text { groups for each virtual community. } \\
\text { Possible to attach relevant documents } \\
\text { or links to external information. }\end{array}$ \\
\hline & Discussion & $\begin{array}{l}\text { Provides support for individual } \\
\text { discussion forum. Possible to attach } \\
\text { relevant documents or links to external } \\
\text { information }\end{array}$ \\
\hline & Event & $\begin{array}{l}\text { Allow announcements of events such as } \\
\text { seminars and courses and the user } \\
\text { registration to the events }\end{array}$ \\
\hline 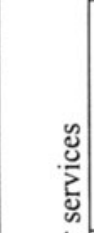 & E-meeting & $\begin{array}{l}\text { Possible to interact with an unlimited } \\
\text { number of participants on a personal } \\
\text { computer. Supports real-time video, } \\
\text { audio, shared application windows, } \\
\text { whiteboard, chat and web-based } \\
\text { presentations }\end{array}$ \\
\hline 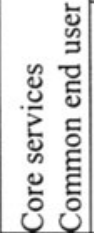 & Information broker service & $\begin{array}{l}\text { Allows the user to define a personal } \\
\text { search profile to be used to search for } \\
\text { product locally or globally. A product } \\
\text { could be a service like flight } \\
\text { reservation, a hardgoods like a book or } \\
\text { a content }\end{array}$ \\
\hline
\end{tabular}




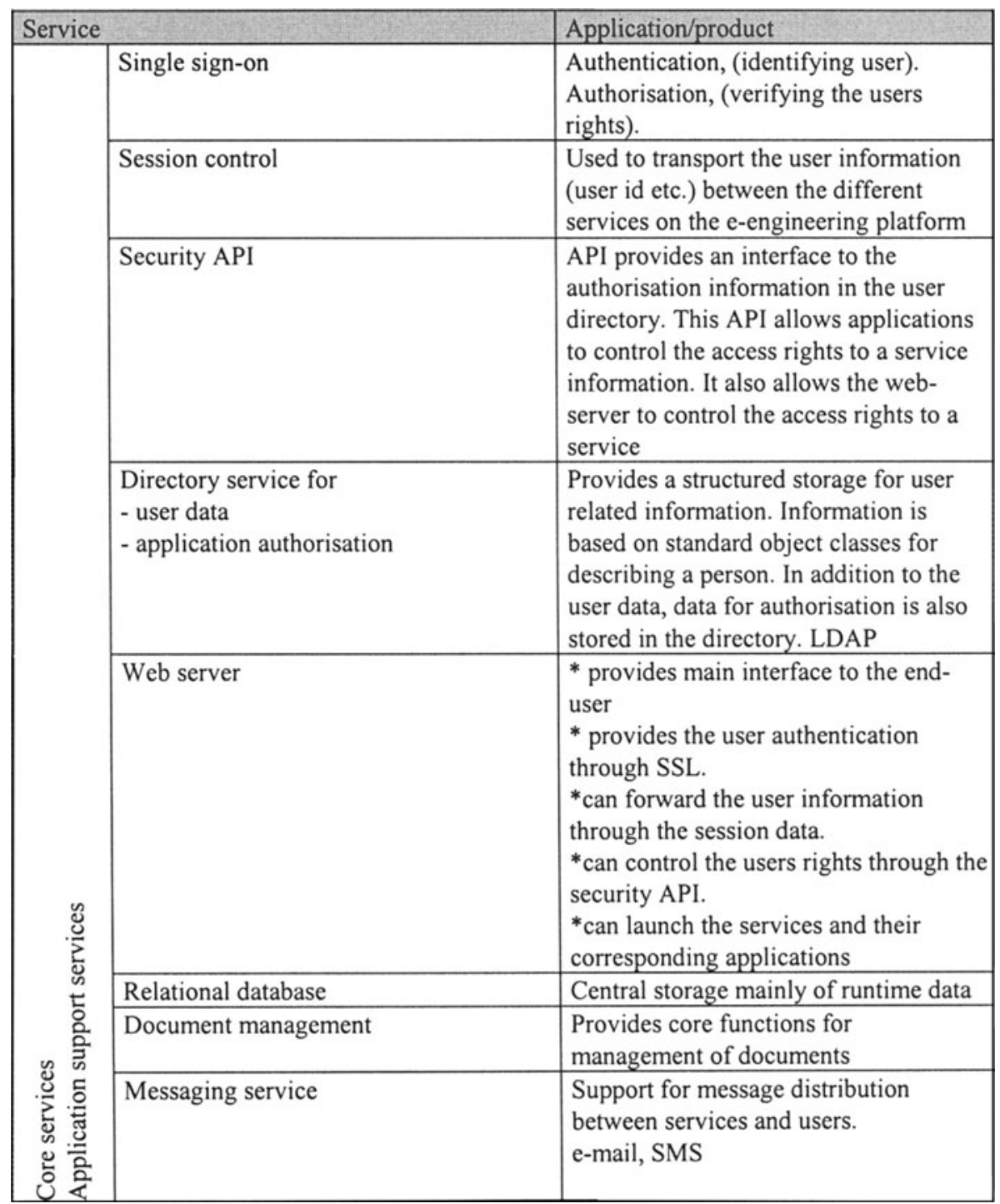

Most of the functions presented are supplied by applications/tools (document management system (FAM), video conferencing(Marratch pro), virtual community (Net-community) supplied by the consortium of the European project mediasite [10]. However these tools have been be integrated in order to form a common collaborative platform.

The integration platform is still under development and needs to be tailored in order to realise all the functions needed to achieve a true Integrated Product Engineering. 


\section{CONCLUSION}

Thanks to the rapid advances in telecommunications and web technologies, more organisations are involved in the process of an extended enterprise creation. Therefore they meet more easily customer demands for high added-value products and services in a global market. Our ecollaborative platform for Product engineering application represents already a means to increase the communication between partners and thus enhance greatly the productivity. However, The issues generated such security, collaborative strategies definitions, accurate data exchange/sharing, interoperability, etc. cannot be solved by technological means alone, but some socio-economic, legal and policy aspects have to be considered.

\section{REFERENCES}

[1]A. Bechina,M. Kullmann, B. Keith., (2000). A Description Logic Model for the Management of Automated Guided Vehicles. In Proceedings of the IFAC Conference on Control Systems Design 2000, Bratislava, Slovak Republic,

[2]A. Bechina,A. daum, N. Howind, , (2000). Report on Platform Specification, DeliverableD7.4, Germany, Mediasite project

[3]A. Bechina,A. daum, (2000). Report on Platform Specification, DeliverableD7.6, Germany, Mediasite project

[4] Camarinha-Matos, L. M., Afsarmanesh, H., (eds) (1999), Infrastructures for Virtual Enterprises. Networking Industrial Enterprises. IFIP TC5 WG5.3 / PRODNET Working Conference for Virtual Enterprises (PRO-VE'99), Porto, Portugal, 27-28 October 1999, Boston: Kluwer Academic Publishers

[5] Decker, Stefan; Daniel, Manfred, Erdmann, Michael; Studer, Rudi: An Enterprise Reference Scheme for Integrating Model Based Knowledge Engineering and Enterprise Modelling. Karlsruhe, Universität Karlsruhe (TH), Institut für Angewandte Informatik und Formale Beschreibungsverfahren; (Bericht 365), 1997.

[6] DogAC, Asuman (ed.): Workflow management systems and interoperability: proceedings of the NATO Advanced Study Institute on Workflow Management Systems heeld in Instanbul, Turkey / Heidelberg : Springer-Verlag, 1998. ISBN 3-540-64411-3 .

[7]Edoardo Iacucci(a), Bertil Axelsson(b) (2000). MediaSite: Web-based Services for Virtual Teams and Communities of Practice in SMEs. ITBM 2000: Information Technology for Business Management, China

[8] GROISS, Herbert; EDER, Johann: Bringing Workflow Systems to the Web. Institut für Informatik, Universität Klagenfurt, Austria.

[9] Wognum, N., Thoben, K.-D., Pawar, K. S. (1999), Proceedings of ICE'99, International Conference on Concurrent Enterprising, The Hague, The Netherlands, 15-17 March 1999, Nottingham: University of Nottingham, ISBN 0951975986.

[10] Mediasite EU project: http://www.mediasite.nu 